\title{
Study on Wuyi Expressway Atmospheric Environment Monitoring System
}

\author{
Yonglin Wang ${ }^{1,2, a}$, Zhiqing $\mathrm{Li}^{3, b^{*}}$,Yingxin Zhou ${ }^{1,2, \mathrm{c}}$, Zhengfu Qian ${ }^{1,2, \mathrm{~d}}$, \\ Hinata Yoichi, ${ }^{4, e}$, Ryu Kou ${ }^{4, f}$ and Shengyuan Miao ${ }^{1,2, g}$ \\ ${ }^{1}$ Yunnan Communications Investment and Construction Group Co., Ltd., Kunming, Yunnan 650228, \\ China \\ ${ }^{2}$ Yunnan Wuyi Expressway Construction Headquarters, Kunming, Yunnan 650300 , China \\ ${ }^{3}$ Key Laboratory of Shale Gas and Geoengineering, Institute of Geology and Geophysics, Chinese \\ Academy of Sciences, Beijing 100029, China ; \\ ${ }^{4}$ Nihon kasetsu Co., Ltd., Hokkaido Sapporo 063-0836, Japan;

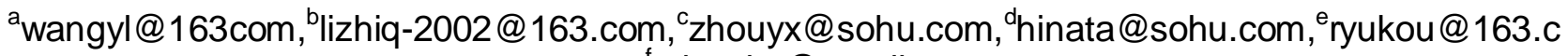 \\ om,'miaoshy@gmail.com \\ * The corresponding author
}

Keywords: Highway construction; Atmospheric environment monitoring system; Real-time monitoring; Network sharing

\begin{abstract}
Nowadays China's expressway undertakings are developing rapidly. While pursuing the development speed, more attention must be paid to the quality of roads and the impact of construction on the surrounding ecological environment, especially the atmospheric quality. This article describes a set of atmospheric environment monitoring system used during the construction of Yunnan Wuyi Expressway, combining atmospheric environmental quality monitoring and water quality monitoring, analyzing the real-time monitoring of PM10, PM2.5, $\mathrm{CO}_{2}$ and wind direction wind speed, temperature, humidity, rainfall. Data can be transmitted to the Internet for network sharing. Through the analysis of the measured results, obtain the changes of PM10, PM2.5, and $\mathrm{CO} 2$ concentrations, which has guiding significance for practical construction.
\end{abstract}

\section{Introduction}

Expressway is one of the most convenient infrastructures in China. In recent years, the rapid development of expressway business has promoted the continuous improvement of the national economy. However, the construction of the expressway will have a great impact on the surrounding ecological environment. Therefore, the environmental monitoring of the expressway project cannot be delayed. Wuyi Expressway is located in Yunnan Province, through the continuous mountainous from Wuding to Yimen, the construction area is densely populated, and the industrial land covers a large area, which greatly affects the environment and ecology during the construction process. So we must follow the principle of maintaining the ecological environment, minimize its impact on the surrounding environment, and comprehensively build a low-carbon and environmentally-friendly expressway to improve the project quality of the Wuyi Expressway. Therefore, real-time monitoring the concentration of environmental pollutants in the construction process and evaluating the environmental status of the area can not only ensure the environmental quality in construction period, but also provide a basis for environmental observation during the operation of the expressway.

Atmospheric environment monitoring system can actualize real-time monitoring of the concentration of certain specific pollutants on the site through computer means, and analyzes and the conditions of the atmosphere environment. The current monitoring methods have changed the data collection from the past to automatic continuous monitoring systems at present [1]. The commonly used monitoring methods include remote sensing monitoring, GIS monitoring and 
internet of things monitoring, these three ways can realize real-time data collection, transmission, and processing. They require a wide range of monitoring, flexible arrangement of monitoring points, and accurate feedback of environmental information in real time [2].

To sum up, a series of research activities, such as environmental observation, data analysis, and early warning in the construction and operation phases, have scientific and reasonable guiding significance for advancing the construction of low-carbon, environmentally-friendly expressways and the sustainable development of the environment. Through the introduction and integration of new concepts, new technologies, and new products, the project can realize a real-time, accurate, stable, intelligent and comprehensive environmental observing system, provide real-time environmental information feedback to the project management department, control and reduce the impact of environment in the construction of expressways, thus comprehensively improve the construction quality of the Wuyi Expressway.

\section{The Construction of Total System}

Overall System Design. The digital monitoring system has the function of digitizing monitoring data and controlling the quality of the atmospheric environment (Liu and Liu et al., 2017) [3]. The overall design of the total system is based on the principle of real-timely grasping the impact of the highway on the surrounding environment during the construction process. Once the on-site monitoring data is exceeded, the situation can be quickly and promptly reported to the executives of the expressway construction headquarters and construction units.

The total system has carried out a series of designs on the aspects of skills, performance, reliability, and network configuration in accordance with the above principles. The equipment of each monitoring system has been set up for special instruments to facilitate the site setup and debugging, especially in the reliability design, the system structure, data backup, and system recovery operations related to the continuity of the anomaly detection, system alarm, and confirmation system restoration are discussed and studied to ensure the practicality of the system. Wireless sensor networks can perform real-time environmental monitoring with high measurement accuracy and have high applicability of atmospheric environment monitoring [5].

Integrated System Construction. The development of the total system includes the selection of instruments for each monitoring system, performance design of monitoring equipment, and individual design of monitoring system servers. After the completion of the total system, the equipment is installed and arranged separately in each specific construction site, and performed tests of the individual systems and comprehensive system to ensure the coordination of the overall system operation. The purpose of the comprehensive test is to confirm if the developed system meets the requirements of the original design. The system confirms it has achieved the performance design requirements by the monitoring function of the environmental monitoring instrument and the normal operation of data storage, data processing, web browser and other functions. In the process of building the total system, in order to avoid or reduce the risk of external network attacks, it set measures such as logging in user restrictions, using complex passwords, setting access restrictions, and using the latest software with known security are taken to keep safe.

The intelligent environment monitoring system consists of environmental sensors, data acquisition and control systems, database servers, and network servers (shown as Fig. 1). The choice of environmental sensors mainly depends on the merits of the identification components, its sensitivity determines the accuracy of the measurement data [7]. The data acquisition and control system collects analog signals and digital signals, and stores them in internal memory and on-site external data memory, they are output as analog signal physical quantities after being processed by environmental sensors. Rainfall is output as a pulse signal, the output monitoring data passed through a wireless local area network (WLAN) or the $4 \mathrm{G}$ mobile communication network, sent from the FTP server to the database server, and then data processing is performed inside the database server. The database server consists of monitoring data update program, ATHENA gateway program, monitoring data, database encryption and communication gateway and so on. The web server consists of data display control software Opera, Port FW, and Global IP (shown as Fig. 2). 
The system is applicable to iOS and Android systems (shown as Fig. 3). The management personnel of highway construction headquarters and construction units can use smart phones to know the environmental data monitored at the construction site and make timely emergency response.

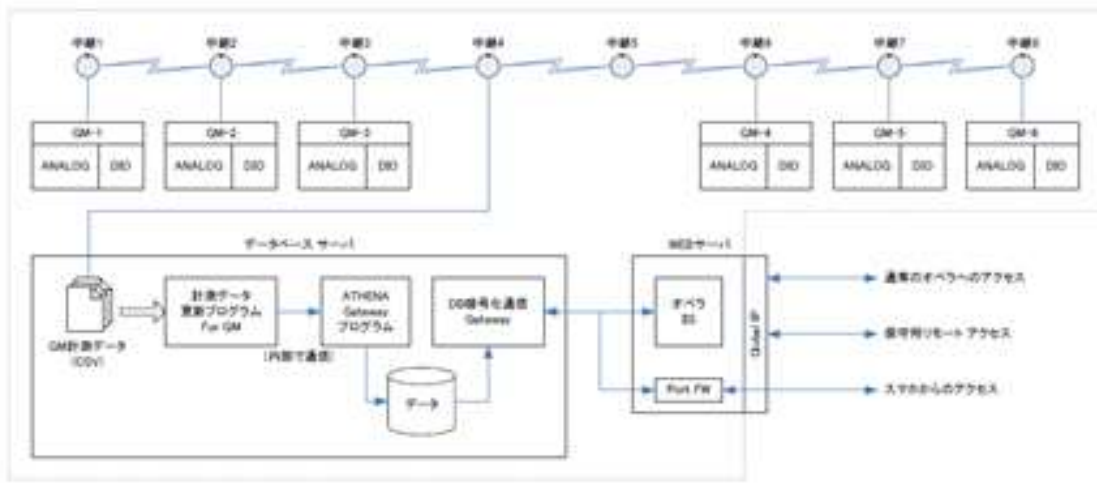

Figure 1. Finite Overall system compostion

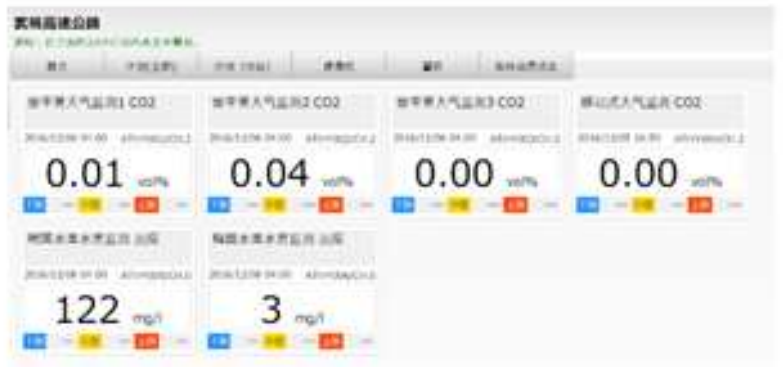

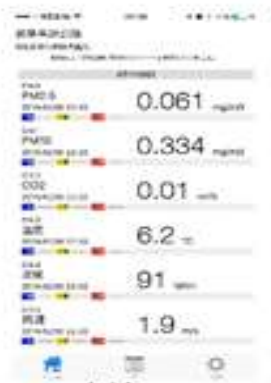

(a)iOS

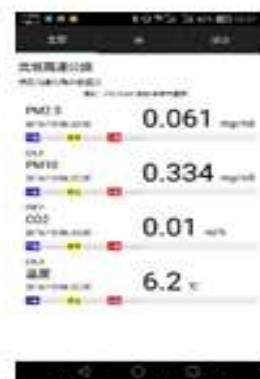

(b)Android

Figure 2. Finite Web browser interface example Figure 3. Finite Smart phone interface example

\section{System construction and settings}

Overall System Composition. The expressway construction project requires the implementation of an atmospheric monitoring system and a water quality monitoring system. The atmospheric monitoring system includes PM10, PM2.5, $\mathrm{CO}_{2}$, wind speed, temperature, humidity, and rainfall monitoring. The water quality monitoring system includes turbidity and $\mathrm{pH}$ monitoring. The expressway is 104 kilometers. It is difficult to fully grasp the environmental conditions of various construction points along the line. To realize the environmental quality of the whole construction period, a mobile vehicle-mounted atmospheric monitoring system was developed to monitor the impact of the entire construction site on the environment along the expressway.

Atmospheric Monitoring System. Atmospheric monitoring system includes PM10, PM2.5, $\mathrm{CO}_{2}$ concentration monitoring and wind direction, wind speed, temperature, humidity and rainfall monitoring. This study is based on the design requirements to control the influence of construction operations on the surrounding environment, and speculates the dispersion of particulate matter in the atmosphere. While monitoring PM10, PM2.5, and $\mathrm{CO}_{2}$ concentrations, it also monitors the change of wind speed, temperature, humidity, and rainfall. For example, when the concentration of PM10 rises, according to the wind direction, temperature, and humidity data, it can be determined if it caused on-site construction or other influences.

Mobile Vehicle-mounted Atmosphere Monitoring System. The total length of the expressway is 104 kilometers, and the limited fixed-point monitoring cannot grasp the impact of the entire construction line on the environment. Therefore, an atmospheric monitoring system that can be installed on the vehicle is developed, the monitoring items include PM10, PM2.5, $\mathrm{CO}_{2}$ 
concentration, temperature and humidity. It equipped with dedicated mobile communication equipment and power conversion devices. In addition, the system is also designed to take into consideration the way of connecting with geographical coordinates, and the position of the monitoring point can be accurately grasped through the GPS coordinates.

Water Quality Monitoring System. The water quality monitoring system is used to monitor the turbidity and $\mathrm{pH}$ of artificial reservoirs downstream at the downstream of construction site. The rainfall around the reservoir will directly affect the flow of water flowing into the reservoir, causing the fluctuation of the water level. In order to reduce the impact of this fluctuation to achieve stable monitoring, the system constructs a floating ball water quality monitoring apparatus, the turbidimeter and the $\mathrm{pH}$ meter are respectively fixed on the two floating ball assembled shelves and remain vertical to the water surface at all times.

Overall System Settings. As shown in Fig. 4, the atmospheric monitoring system is located at three locations on the Anfengying junction overpass, this overpass is the interchange between Hangzhou Expressway and Wuyi Expressway. Since the surrounding area of the main structure of the overpass has a population living area, it is necessary to control the discharge of PM10, PM2.5, and $\mathrm{CO}_{2}$ during the construction process. In addition, the system could continue to monitor the air pollution caused by traffic vehicles on the road after Wu Yi Expressway was put into use. The sensor setup status and details of the atmospheric monitoring system shown as Fig. 5,6,7.

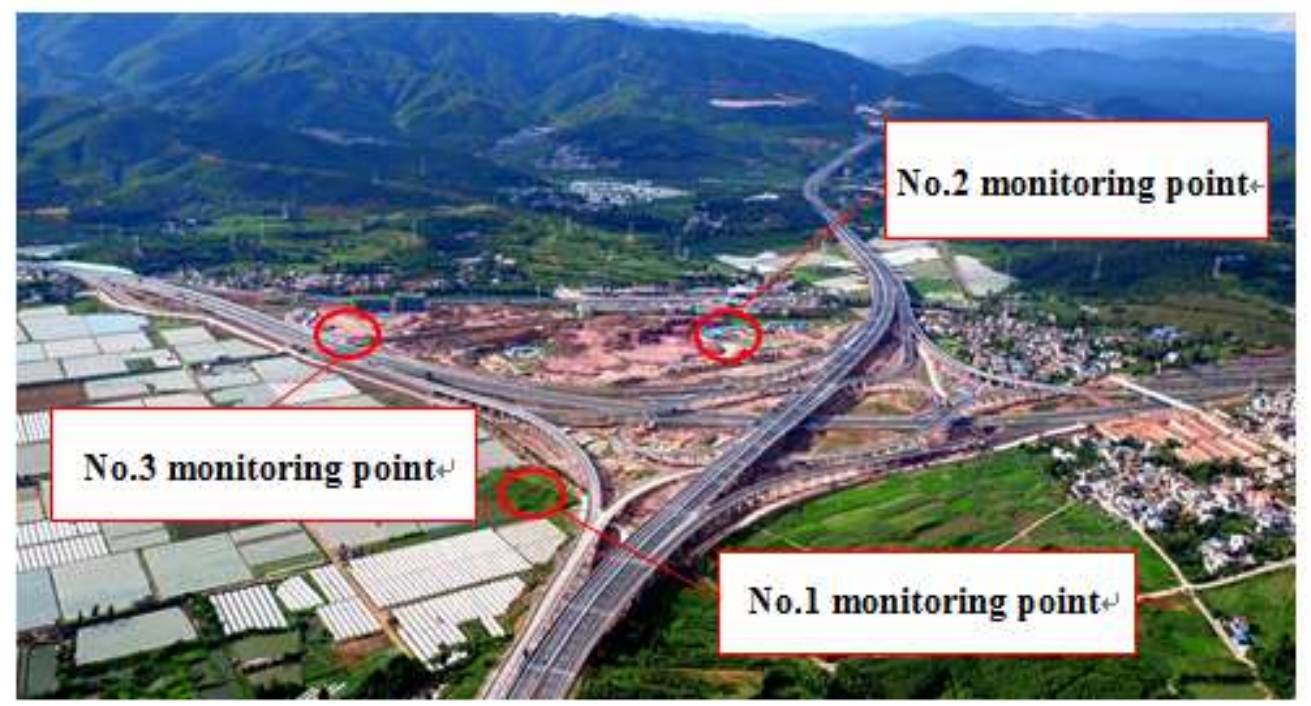

Figure 4. Finite monitoring points arrangement of Anfengying junction

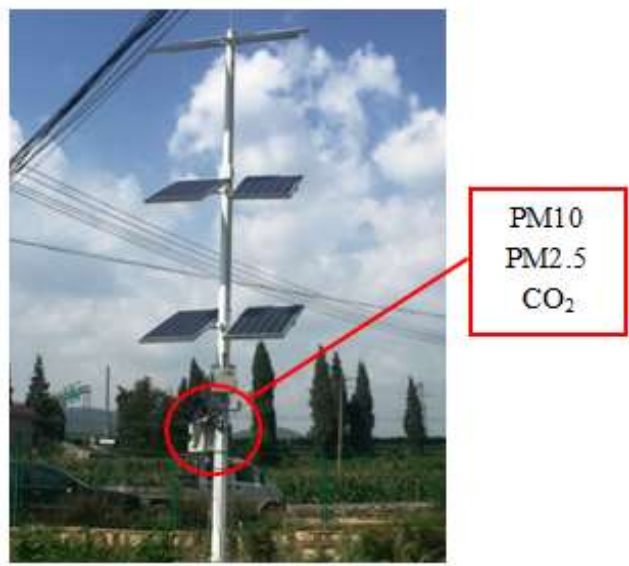

Figure 5. Finite Setting of the atmospheric monitoring system Figure

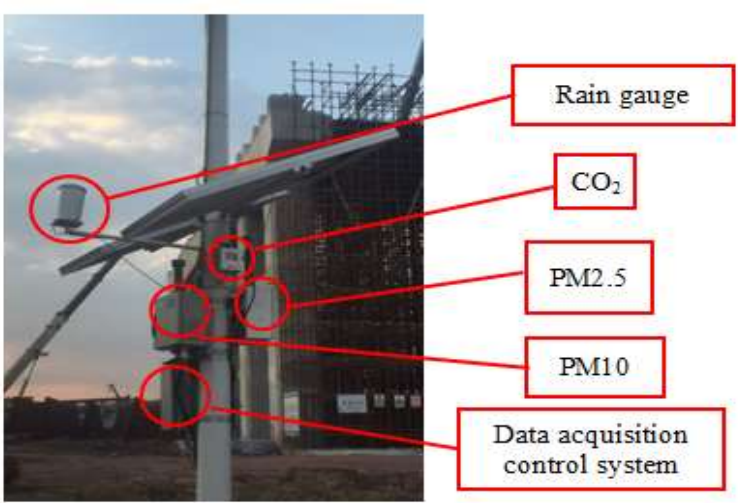

Figure 6. Sensor setting details 


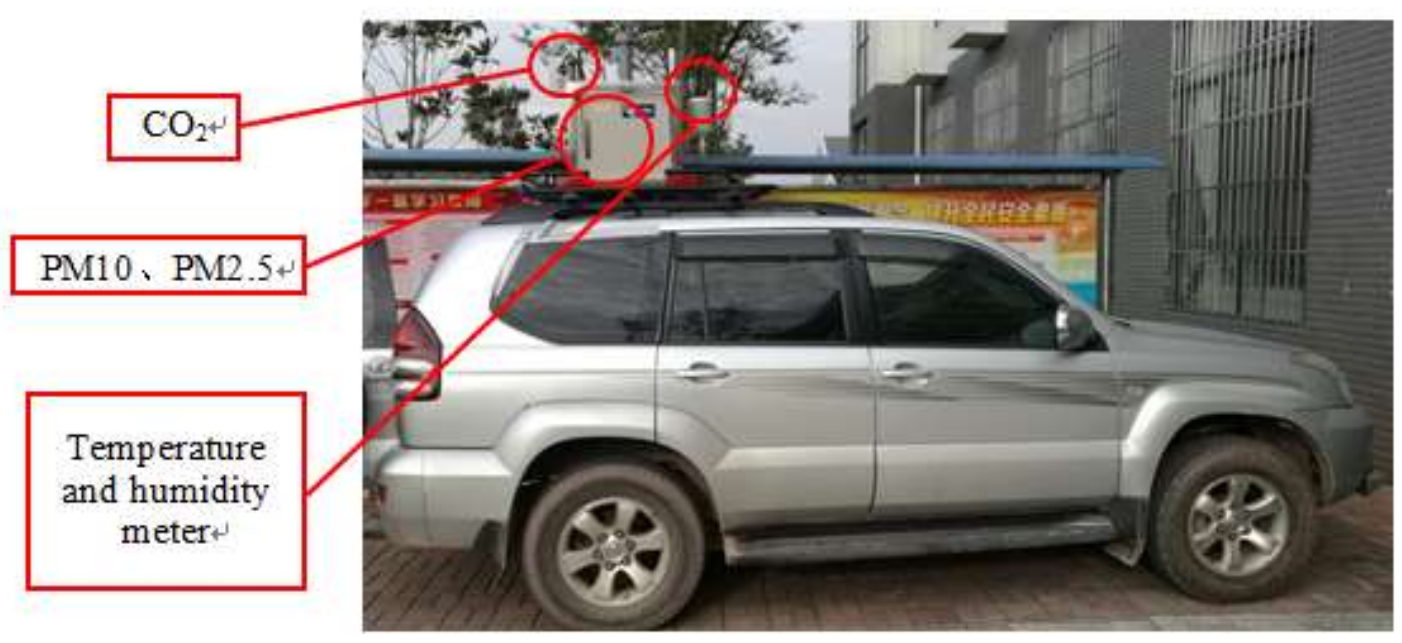

Figure 7. Fintie Mobile vehicle-mounted atmospheric monitoring vehicles

The water quality monitoring system was set up at two locations, the Sentinel Reservoir and the Meizen Reservoir. The sensor setup of status and details of the water quality monitoring system shown as Fig. 8,9.

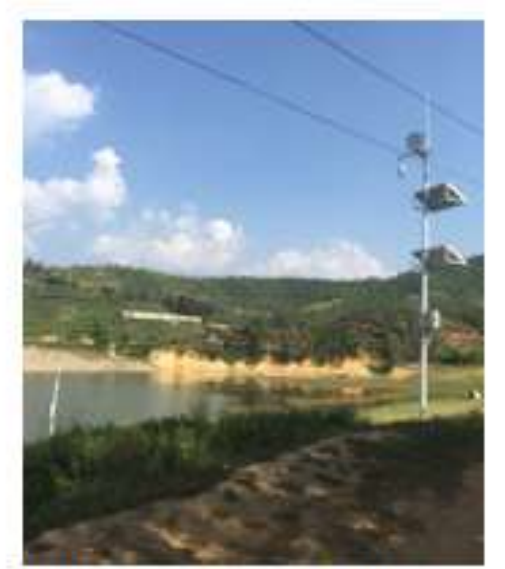

Figure 8 Settings of the water monitoring system

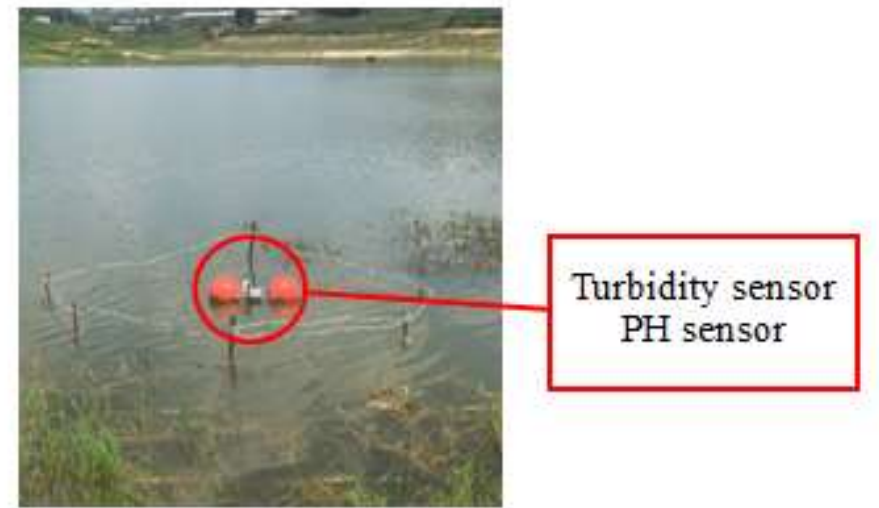

Figure 9 Floating ball turbidity meter and $\mathrm{pH}$ meter

\section{Main Sensor Characteristics}

PM10 Sensor. Considering the practicality and economy of the project, the light scattering dust meter was selected as the PM10 sensor. This type of dust meter utilizes the principle that the amount of scattered light generated by the inhaled particulate matter changes in proportion to the mass concentration, the amount of scattered light is converted into an electrical signal and detected as the mass concentration of the particulate matter. The instrument has the characteristics of stable light emission, stable light receiving accuracy, stable suction pump suction amount, and an automatic cleaning structure for cleaning the optical part by conveying clean air, so that stable detection accuracy can be obtained. In addition, the instrument is equipped with a heater between the external air intake port and the internal host air intake port to reduce detection errors caused by tiny water molecules such as fog.

PM2.5 Sensor. The PM2.5 sensor adds a centrifugal particle separation device based on the PM10 sensor in order to coarse particles in advance.

$\mathrm{CO}_{2}$ Sensor. The $\mathrm{CO} 2$ sensor uses a non-dispersive infrared absorption type, which utilizes the characteristic that different gases absorb infrared rays of a specific wavelength. When the sample gas is irradiated with infrared rays, measure the absorption of a specific wavelength, the composition and concentration of the sample gas can be detected. This instrument uses full 
wavelength infrared light emitted directly from the light source.

Turbidity Sensor. A 0-100 degree of formalin turbidity sensor was used. The instrument is equipped with a cleaning blade, which can automatically clean the detection window on a regular basis to achieve continuous monitoring.

pH Sensor. The instrument adopts a sleeve-shaped structure in the liquid liaison section, which improves the stability and reproduction of the detection and enables high-precision $\mathrm{pH}$ detection.

\section{Analysis of Monitoring Data}

There is an example of the PM2.5 and PM10 concentration results of atmospheric monitoring at Anfengying junction and analyzed in 24 hours a day (shown as Fig. 10,11). The value of PM2.5 concentration at the No. 2 monitoring point at $6: 00 \mathrm{a} . \mathrm{m}$. was $0.022 \mathrm{mg} / \mathrm{m}^{3}$. Along with the progress construction of the day, the concentration began to gradually increase, reaching a maximum value of $0.068 \mathrm{mg} / \mathrm{m}^{3}$ at $15: 30 \mathrm{p} . \mathrm{m}$. The average wind speed was about $2 \mathrm{~m} / \mathrm{s}$ on that day, and the wind direction was south-southwest. Therefore, the PM2.5 concentration at the No. 2 monitoring point on the northern side of Anfengying junction was increased. There is no significant change in the value of the No. 3 monitoring point at the west side of Anfengying junction, indicating that the impact of the construction is small. The change trend of PM10 concentration is similar to that of PM2.5, and the concentration value begins to rise at the beginning of construction. The PM10 concentration at the NO.1 monitoring point of Anfengying junction was $0.355 \mathrm{mg} / \mathrm{m}^{3}$ at $14: 10$ p.m. No. 2 monitoring point reached a peak concentration of $0.192 \mathrm{mg} / \mathrm{m}^{3}$ at $12: 00 \mathrm{a} . \mathrm{m}$. and $0.188 \mathrm{mg} / \mathrm{m}^{3}$ at 15:00 p.m. No increase in the PM10 concentration at the No. 3 monitoring site as the construction began. The integrated humidity curve shows that when the humidity decreases, the concentration of suspended particles gradually increases, so maintaining a relatively humid environment is conducive to the improvement of the environmental quality.

The results of atmospheric monitoring of $\mathrm{CO}_{2}$ concentration in Anfengying shows an upward trend at night and a downward trend during the day (shown as Fig. 12). The average concentration of $\mathrm{CO}_{2}$ for one month in October 2016 was 378 ppm. The maximum concentration reached 459 ppm at 5: 40 p.m. on October 8 and the minimum concentration was 311 ppm at 11:50 a.m. on October 20 . The daily $\mathrm{CO}_{2}$ concentration varies from $350 \mathrm{ppm}$ to $410 \mathrm{ppm}$. The analysis shows that the increase of $\mathrm{CO}_{2}$ concentration in nighttime is due to the smaller absorption of $\mathrm{CO}_{2}$ by plants and reaching a maximum around 3:00 p.m. to next early morning. The absorption of $\mathrm{CO}_{2}$ by photosynthesis in daytime plants showed a downward trend. This change indicates that the construction has little effect on the $\mathrm{CO}_{2}$ concentration.

The concentration changes of PM2.5, PM10, and $\mathrm{CO}_{2}$ within the entire construction period can be grasped by the mobile vehicle-mounted monitoring system (shown as Fig. 13.), the relatively high-concentration segments within a certain time range can be obtained so that targeted measures can be taken.

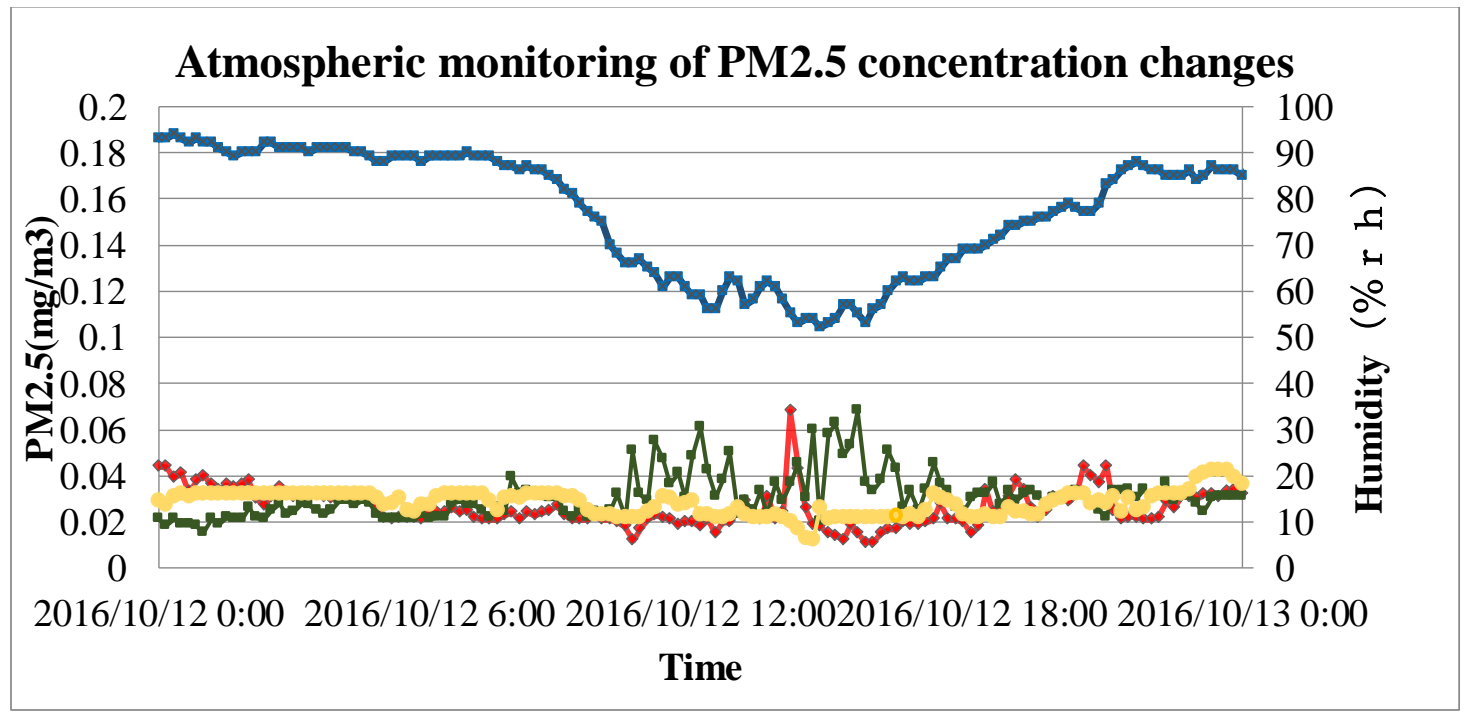


Figure 10. Finite Atmospheric monitoring of PM2.5 concentration changes

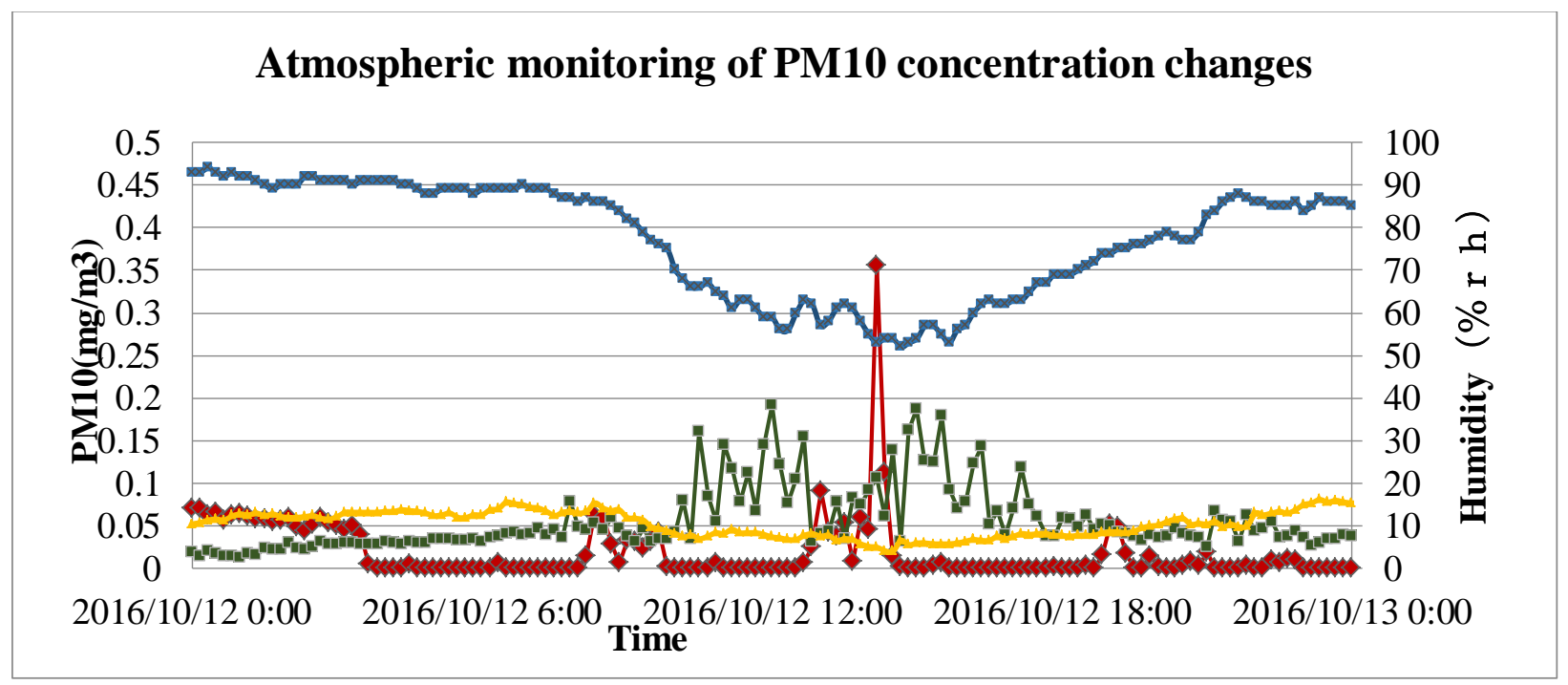

Figure 11. Finite Atmospheric monitoring of PM10 concentration changes

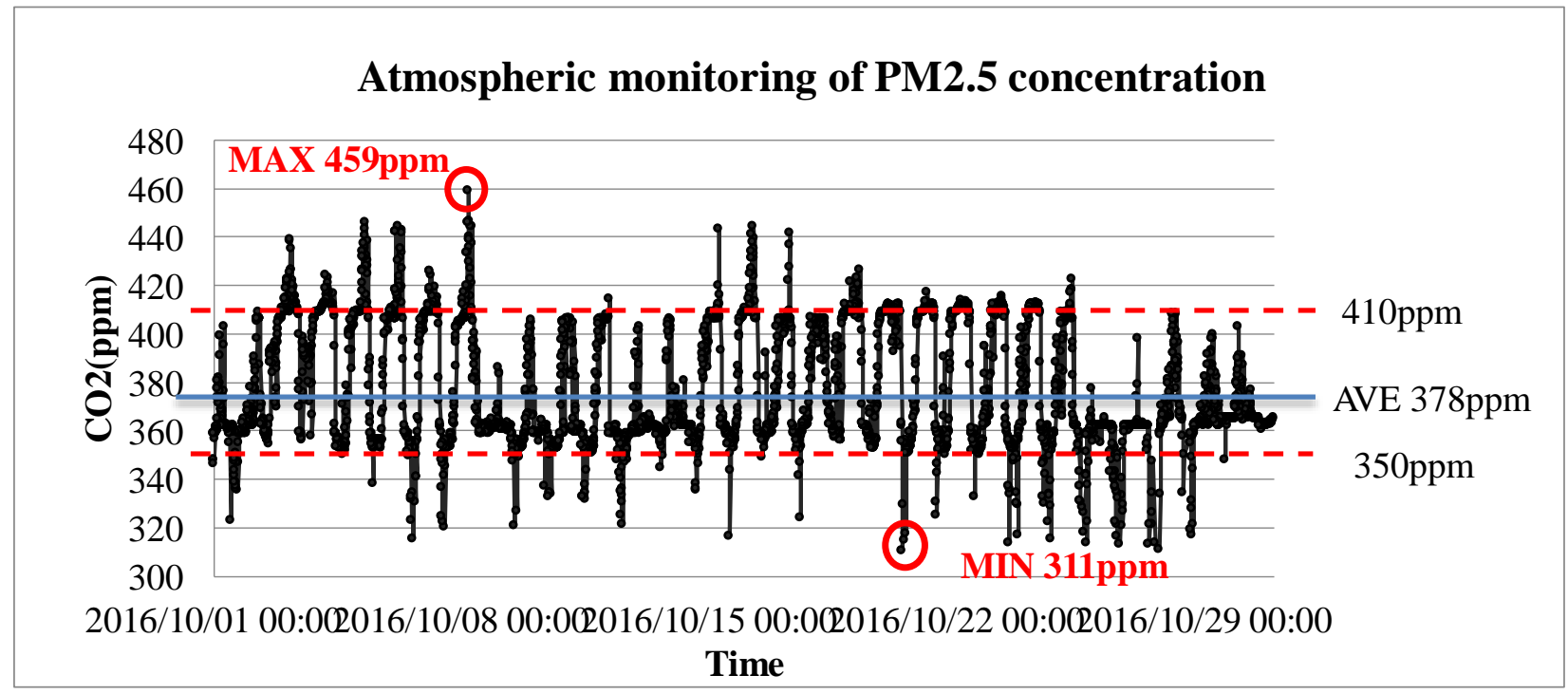

Figure 12. Finite Atmospheric monitoring of PM2.5 concentration changes

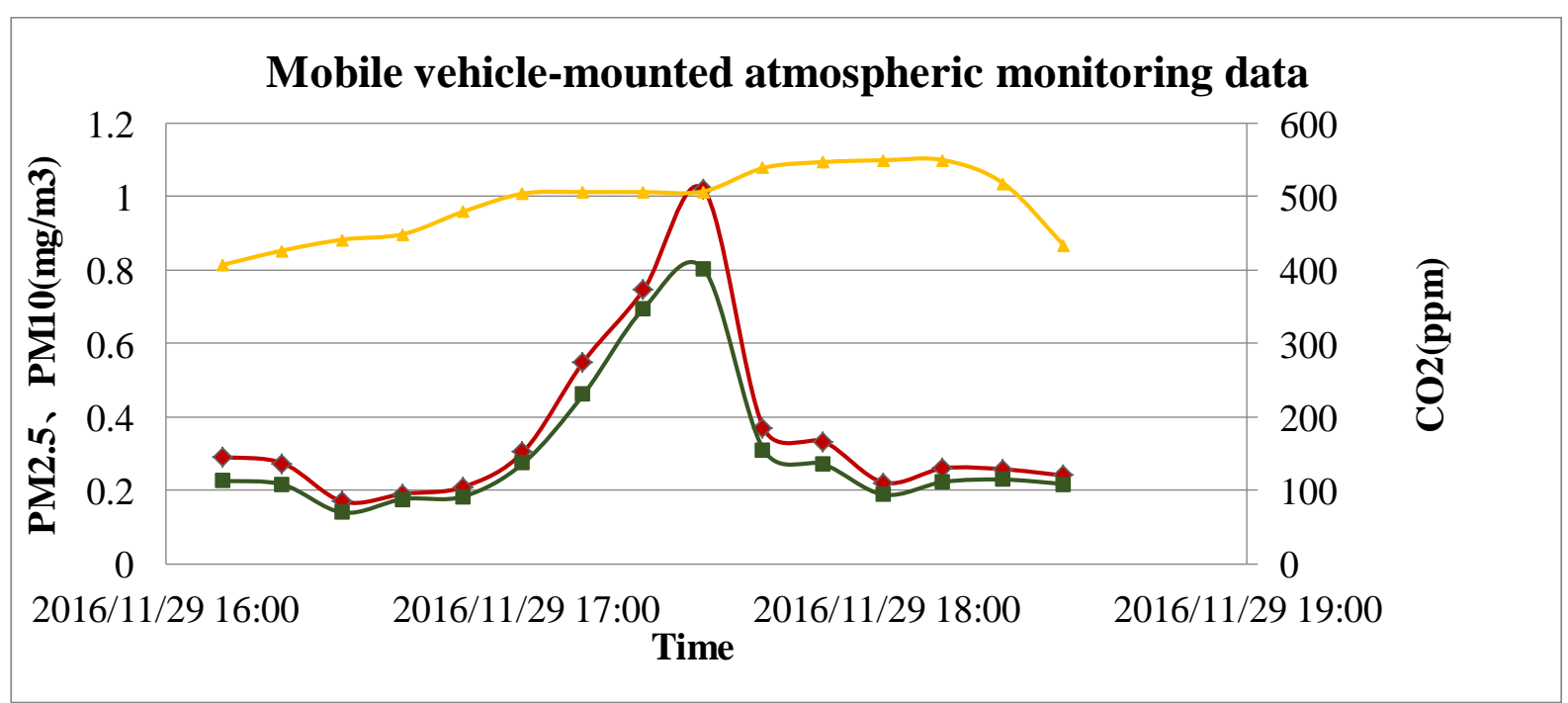

Figure 13. Finite Mobile vehicle-mounted atmospheric monitoring data 


\section{Conclusions}

(1) The project has achieved environmental monitoring of the construction and operation phases of Wuyi Expressway through the designated atmospheric environment monitoring system, water quality monitoring system and mobile vehicle-mounted atmospheric monitoring system, thus ensuring that the surrounding ecological environment cannot be damaged.

(2) Highly stability of the monitoring system, good coordination among the individual systems and real-time data sharing through the network, can remotely grasp the environmental information and feedback to the managers of the highway construction headquarters and construction supervisors to take timely and targeted measures.

(3) The concentrations of PM10 and PM2.5 are relatively low at the early morning of each day, and increase with the progress of construction. When the humidity of the surrounding environment is reduced, the concentration content will be grown up. Wind speed and direction also have influence. The concentration of $\mathrm{CO}_{2}$ within a certain range shows a regular that increased at night and decreased during the day related to the photosynthesis of plants. Therefore, the construction process had no significant effect on the change of $\mathrm{CO}_{2}$ content.

\section{References}

[1] C.M. LI: Henan Technology, Vol.24 (2016) No.07, p.24-26.

[2] Q.Y. Gao: Science \& Technology Vision, (2015) No.16, p. 194-196.

[3] Z.Y. Liu, G. Liu and Q. Li: Nature Science, (2017) No.2, p. 195.

[4] X.L. Wang: Technology Innovation and Application, (2016) No.7, p.159.

[5] L. Ding, W.X. Zhu and D.X. Jiang: Transducer and Microsystem Technologies, Vol.32 (2017) No.10, p. 74-76.

[6] C.B Sun Chunbao. Environmental Monitoring Principles and Technology. (Mechanical Industry Press. China 2007).

[7] W. Pang, Y.T. Zhu and W.J. Jiang: Resource Development\&Market, Vol.28(2012) No.7, p. 583-585.

[8] J.K. Liu: Resources Economization \& Environment Protection, Vol.67 (2013) No.9, p. 110. 